\title{
Incorporating Human Aspects into Groundwater Research and Policy Making: A Soft and Critical Systems Thinking Approach
}

\author{
Sondoss Elsawah and Joseph H.A. Guillaume
}

\begin{abstract}
Groundwater management issues present a serious challenge partly because of the complexity and uncertainty that human elements (i.e. cognitive, social, cultural and political) bring into the problem, as well as our limited capacity to fully comprehend and deal with such elements and their interactions with the biophysical systems. Whereas there is a wide recognition of the importance of stakeholder participation for the design and implementation of effective policies, the ongoing depletion of groundwater and disputes surrounding management policies suggest the need for better participatory mechanisms. This raises the question of how human elements can be incorporated into groundwater policies. Whereas there is no single discipline that can provide answers for such crucial research and policy questions, this chapter argues that systems thinking (especially soft and critical approaches) has the potential to provide a framework of theories, methods and example applications to help incorporate human elements into groundwater management and research. This chapter aims to give an overview of systems thinking by firstly describing the theory, distinguishing between hard, soft and critical systems thinking approaches. Secondly, we discuss the importance of mixing methods from these approaches and evaluating
\end{abstract}

\footnotetext{
S. Elsawah $(\bowtie)$

School of Engineering and Information Technology, University of New South Wales, Canberra, Australia

Integrated Catchment Assessment and Management Centre, Fenner School of Environment and Society, Australian National University, Canberra, Australia e-mail: S.elsawah@adfa.edu.au
}

J.H.A. Guillaume

Integrated Catchment Assessment and Management Centre, Fenner School of Environment and Society, Australian National University, Canberra, Australia

Water and Development Research Group (WDRG), Aalto University, Tietotie 1E, Espoo 02150, Finland 
'process' and 'outcomes' when applying them. Thirdly, we review four example applications, and highlight their relevance to groundwater management systems.

\subsection{Introduction}

Groundwater research and policy making are grappling with many interconnected and interdependent issues including:

- Finding ways to anticipate and adapt to climate change impacts on groundwater resources, and dependent social-ecological systems, including severe impacts from climatic hazards such as prolonged droughts;

- Allocating available water among competing consumptive and environmental water needs especially at times of scarcity;

- Identifying and dealing with risks to groundwater health (quantity and quality) caused by cumulative and delayed impacts of human activities;

- Establishing the public's trust and acceptance of management decisions, and the credibility of underpinning science in situations where values and science are highly contested, and data are limited;

- Building the adaptive capacity of individuals, communities, and institutions to communicate, learn, and self-adjust in order to respond timely to incremental and abrupt changes in resource conditions

There is a wide consensus that contemporary water and groundwater management issues are defined as wicked problems (Rittel 1972), messes (Ackoff 1974), or resource dilemmas (Ison et al. 2007). These terms express the observation that managing groundwater issues is a vexing challenge owing to a constellation of reasons, many of which are caused and/or amplified by the human rather than the biophysical elements of the system. First, the resource behaviour is driven by the collective outcomes of decisions and actions made by different actor groups (i.e. stakeholders, policy makers, and scientists) where individuals and agencies within and across groups interact at different levels of the governance system (see Fig. 24.1). Second, there is no well-defined set of goals or priorities. Stakeholders have multiple, many times conflicting, views about the resource. For example: how they envisage the future of the groundwater resource systems, how much weight is to be given to different knowledge sources and viewpoints, what are considered feasible and acceptable management decisions. Third, managed systems, both human and biophysical, do not respond to management initiatives in ways that are consistent or predictable. Implementing a management intervention may create a new set of problems that may only become evident when considering the problem situation across broader spatial and temporal ranges (Mason and Mitroff 1981). For example, effects of a single mine on groundwater levels might seem to be acceptable. However, aggregated effects from multiple mining sites may interact with 


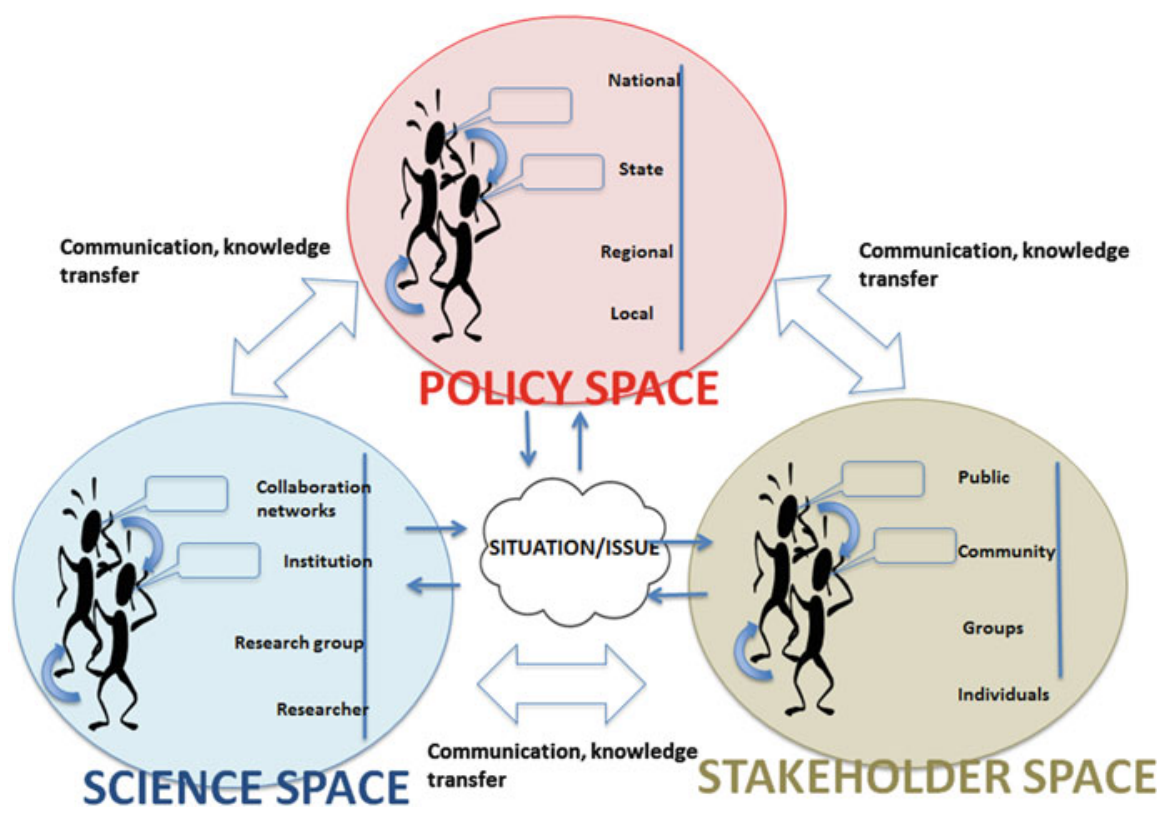

Fig. 24.1 In resource dilemmas, the resource behaviour is driven by the collective outcomes of decisions made by multiple groups at different levels of the governance system

other pressures (e.g. other development activities) leading to cumulative and long term effects at a regional level. Fourth, there is no silver bullet or a final solution for managing wicked problems. Groundwater policies (e.g. allocation plans) need to be continuously monitored and periodically reviewed to cope with emergent changes in the resource conditions and stakeholder values. Finally, we (as scientists, resource users, managers, and policy makers) have limited capacity (e.g. cognitive, social) to understand and manage such complexity and uncertainty. Reynolds (2011) argues that we often fall into three conventional thinking traps that hinder us from appreciating the nature of the situations on hand:

1. Reductionism: our tendency to focus on individual parts and symptoms of a problem, and overlook root causes and interrelationships. For example, traditional groundwater allocation policies are often framed around identifying hydro-geological aquifer limits, and marginalising the cognitive and sociocultural context at which the policy is embedded.

2. Dogmatism: our tendency to take a single perspective on the system, and overlook other viewpoints. This leads to excluding or marginalising policy impacts on particular stakeholder or interest groups.

3. Managerialism: our tendency to overlook the limited capacity of employed interventions (e.g. instruments, measures, methods) in dealing with the sheer uncertainty and complexity of the whole situation. 
The motivation for this chapter stems from two premises. First, the field of systems thinking (especially soft and critical) has the potential to improve our capacity to understand and manage the human (i.e. cognitive, social, cultural, and political) elements in wicked water and groundwater issues. Systems thinking approaches provide a holistic framework (of theories, methods, and tools) that can help unlock key management issues and interrelationships from multiple perspectives. In systems thinking, the key assumption is that bringing together different views may lead to building shared, multi-dimensional, and rich understanding of the situation, which may therefore, lead to developing sustainable (i.e. economically-viable and socially-accepted) policies. This assumption presents an opportunity for groundwater policies that cry out for better and more explicit ways of incorporating and linking the human aspects to the groundwater conditions (Richardson et al. 2011).

The second premise motivating this chapter is the perceived lack of studies that explicitly address the systems applications in sustainability problems (including groundwater). Midgley and Reynolds (2004) argue that for every paper on environment management that is explicit about the use of Operations Research/Systems Thinking (OR/ST) methods, there are "at least" five that use similar OR/ST methods, claiming "methodological innovation" without referencing OR/ST. The ideas are clearly useful. Even for authors who mention a systems approach as a research framework (e.g. Bosch et al. 2007), the discussion is often limited to the conceptual idea of systems thinking without explicitly explaining the in-depth implementation details, and how the work links to existing theories and methodologies. Therefore, we aim to promote use of systems methods in groundwater management explicitly rather than reinventing the wheel, and with rigorous reference to theory rather than referring to vague concepts.

The chapter is structured as follows. First, we trace the evolution of the systems idea through the hard, soft, and critical developments (Sect. 24.3). Next, we discuss two important topics in systems approaches: multi-methods and evaluation (Sect. 24.4). In Sect. 24.5, we complement the theoretical overview with a set of selected case studies to shed some light on different implementations of systems thinking and their relevance to groundwater research and management. Finally, we wrap up by drawing some lessons from systems thinking literature and case studies.

\subsection{The "Systems" Idea}

The systems idea is not new, but can be originally traced back to Aristotle's dictum that "the whole is greater than sum of the parts." The contemporary notion of systems can be found in General Systems Theory (GST) which recognizes the importance of interactions and organization (Von Bertalanffy 1950). Since the formulation of GST, the systems idea has developed in two main directions. The first applied the systems idea in biology and ecology. The second resulted in the development of problem solving methodologies, which have evolved through three 
Table 24.1 Summary of the three waves of development in systems thinking approaches

\begin{tabular}{l|l|l|l}
\hline $\begin{array}{l}\text { Point of } \\
\text { comparison }\end{array}$ & Hard & Soft & Critical \\
\hline System & $\begin{array}{l}\text { A system is a } \\
\text { well-defined } \\
\text { entity that has } \\
\text { clear function }\end{array}$ & $\begin{array}{l}\text { A system is a cognitive and } \\
\text { social construct that is not } \\
\text { independent from the } \\
\text { observer }\end{array}$ & $\begin{array}{l}\text { A system is defined by a } \\
\text { boundary that may be } \\
\text { alienating individuals or a } \\
\text { particular social group }\end{array}$ \\
\hline Purpose & $\begin{array}{l}\text { Predicting, } \\
\text { optimising, and } \\
\text { controlling } \\
\text { outcomes }\end{array}$ & $\begin{array}{l}\text { Develop a meaningful } \\
\text { understanding, learning }\end{array}$ & $\begin{array}{l}\text { Empowering stakeholders } \\
\text { to overcome power } \\
\text { imbalances and social } \\
\text { inequities }\end{array}$ \\
\hline Researcher & $\begin{array}{l}\text { Outside } \\
\text { observer }\end{array}$ & Participant & $\begin{array}{l}\text { Participant, and sometimes, } \\
\text { enabler for change }\end{array}$ \\
\hline Models & $\begin{array}{l}\text { Accurate } \\
\text { representation of } \\
\text { the real world } \\
\text { system }\end{array}$ & $\begin{array}{l}\text { Interpretations or } \\
\text { intellectual construct to } \\
\text { inform debate and learning } \\
\text { about possible changes }\end{array}$ & $\begin{array}{l}\text { Interpretations that are used } \\
\text { to surface and question } \\
\text { assumptions about values, } \\
\text { power, and knowledge } \\
\text { during a public or corporate } \\
\text { dialogue }\end{array}$ \\
\hline
\end{tabular}

waves of thinking: hard, soft, and critical (see Table 24.1). We give an overview of these developments in the following sub-sections.

\subsubsection{Hard Systems Approaches}

During and after World War II, hard systems thinking approaches (optimisation, simulation, systems engineering, systems analysis) appeared as powerful analytical methodologies for solving real world problems. Hard system approaches have been long and widely used to analyse groundwater problems, such as Ayvaz and Elçi (2014). Hard approaches share the following assumptions (Checkland 1981):

- There is a "problem" that can be exhaustively formulated in terms of welldefined objectives and actions that can be optimised or (at least) improved.

- Success in applications depends on quantification of variables and the creation of mathematical formulations that specify the relationships between variables.

- Our knowledge (including models) and language perfectly describe the real world.

- Systems have objective boundaries which are "given" by the structure of reality (Checkland 1983).

- Stakeholders are passive entities who share common views, values and objectives (Rosenhead and Mingers 2001).

- An analyst is an independent observer who perceives the world as a set of interacting components or sub-systems. The analyst's efforts are directed in a systematic search for the most efficient means to achieve objectives. 
In the early 1970s to the mid 1980s, hard systems approaches came under a lot of criticism for their inability to deal with problems that arise in contexts that are highly complex and involve multiple stakeholders (Dando and Bennett 1981). Many authors, such as Churchman (1970a), reject the view that a system has an objective boundary that is independent of human perspectives. System boundaries are social and subjective constructs. Thus, setting a system's boundary is a critical choice about what the study considers to be relevant knowledge and legitimate decision makers. To account for multiple perspectives, the analysis boundary should be pushed out by "sweeping in" divergent views (Churchman 1970b).

\subsubsection{Soft Systems Approaches}

In response to the attack on hard approaches, soft systems thinking appeared as an alternative approach capable of addressing complex and unstructured situations as it places human and social considerations at the core of systems management. The fundamental distinction between hard and soft systems thinking lies in the way they address the philosophical question about the nature of reality and the nature of knowledge (Checkland 1999). In soft systems thinking, the word systemic is no longer applied to the world but to the inquiry process to explore this world. This view implies that systems thinking remains only as a way of describing knowledge about the world rather than an objective reality (Checkland 1983). For more details, we refer the reader to Mingers (2003) who presented and compared the philosophical and methodological assumptions underpinning a multitude of hard and soft systems approaches.

In the soft view, it is necessary to engage in an iterative process of systemic inquiry and learning (which may be ongoing) to develop a meaningful understanding of the situation (Checkland 1985). To build a meaningful understanding, we need to understand the cultural and social aspects of the situation, as well as the purpose, interpretations, and actions of stakeholders. This includes all people who may affect or be affected by the action outcomes, including the researcher(s). The soft approach takes the view that scientists bring their own values and subjective interpretations with the aim of intervening within the system. Intervention is defined as "purposeful action by an agent to make change" (Midgley 2000). Active stakeholder engagement and an active researcher role are common pillars of soft systems and also action research. For a detailed discussion about the links between systems approaches and action research, readers are referred to Flood (2010).

Within the soft systems approach, several methodologies, known as Problem Structuring Methodologies (PSM), have been developed in the literature, including:

- Soft Systems Methodology (SSM) (Checkland 2001)

- Cognitive Mapping (CM) for Strategic Options Development and Analysis (SODA) (Eden and Ackermann 1998)

- Viable System Model (Beer 1989)

- Visioning choice methodology (O’Brien and Meadows 2007) 
Whereas PSMs have different forms, they share four generic phases (Mingers 2000):

1. Appreciation of the situation as perceived by stakeholder groups

2. Analysis of the structure that generates the perceived situation

3. Assessment of ways of changing the situation into more desirable conditions

4. Action to implement change, and achieve desired outcomes.

PSMs use models/modelling in a heuristic fashion, as learning aids or artefacts that help system stakeholders to co-construct a meaningful understanding, but are never taken to represent reality.

\subsubsection{Critical Systems Thinking}

Soft systems thinking and PSMs have been criticized for not being able to address the question of power relations, how they influence the problem situation, and how they are perceived by system actors. This has resulted in a third wave of systems approaches: Critical Systems Thinking (CST) (Ulrich 2000; Jackson 2006). CST rests on the key notion of "boundary judgment", and how it determines how people perceive and judge a particular situation (in relation to what is and what ought to be the case) (Midgley 2000). Setting a system boundary is a critical choice about what the study considers to be relevant knowledge and legitimate decision makers. Ulrich (1994) argues that exploring boundaries through dialogue among stakeholders make the analysis more "rational" and robust than an external group of experts (e.g. scientist and policy makers) imposing their own values. Midgley (2000) argues that boundary setting is deeply underpinned by a value judgment; and conflict arises when two or more value/ethical systems come into tension. Boundary selection therefore has ethical implications (Midgley 1992). People draw a boundary around issues they perceive as sacred or central. Issues outside their boundary are regarded as subsidiary, which marginalises people that hold that view. From this perspective, CST aims to explore and make explicit different boundary judgments, and help justify why a particular boundary judgment is selected. It proposes a dialogical framework to allow for collective reflection to acknowledge and negotiate sources of motivation, power, knowledge and legitimation.

Inspired by the critical systems idea, several methodologies have been developed in the literature including:

- Critical systems heuristics (CSH, (Ulrich 1994))

- System of systems methodologies (Jackson 1999)

- Systemic intervention (Midgley 2000) 


\subsection{Multi-Method and Evaluation in Systems Approaches}

The design and implementation of systems thinking interventions depends on choosing effective methods and allowing for an adaptive process. In this section, we discuss two key topics to achieve this aim: use of a multi-method approach and evaluating systemic interventions.

\subsubsection{Use of a Multi-Method Approach}

The debate about the three waves of systems thinking has moved away from arguing the strength of each wave to recognizing that the three waves take different, but not incompatible, perspectives on the world. This view has resulted in the rise of multi-method/multi-methodology as a framework to accommodate different views of systems (Mingers and Leroy 2010). In the context of this chapter, we will use the term multi-method to denote the broad idea of combining methodologies and/or methods (i.e. hard, soft, and critical) within a real-world intervention (Mingers 2000). Multi-method is increasingly regarded as an essential framework for dealing with wicked and turbulent environments (Mingers 1997).

Wicked problems have multiple dimensions: physical or material, personal and social dimensions. Multi-method strengthens the inquiry process and provides multiple lenses for exploring different aspects of multi-dimensional situations. Whereas the intervention process passes through a number of phases, some methods however can be more useful than others for different phases. Pulling the two ideas together, Mingers and Brocklesby (1997) developed a framework to map out how systems methods can be used to examine the problem dimensions across the different intervention phases. Several research directions have stemmed from the multi-method idea, such as: "coherent pluralism" (Jackson 1999), "pragmatic pluralism" (White and Taket 1997), and "creative design of methods" (Midgley 1990). Whereas these approaches share the idea of using multi-method, they have different view about how methods are selected and employed. Kotiadis and Mingers (2006) identified two strands in multi-method research: (1) those who think that methods and methodologies can be effectively mixed-and-matched to strengthen the inquiry (sometimes referred to as pragmatists); and (2) others who are concerned about the incommensurability of paradigms, and accept multimethod legitimacy only under the condition that it respects the theoretical underpinning of the process used to combine methods. For an overview about the evolution of multi-method theory, readers are referred to Zhu (2011). In practice, there have been different forms of applying multi-methods, such as using methods in parallel (e.g. use of two problem structuring methods at the same time to inform each other) or in series (e.g. use of outputs from problem structuring to inform the design of a numerical model). 


\subsubsection{Evaluating Systemic Interventions}

The topic of evaluating systemic methods has gained increasing attention in the literature (Midgley et al. 2013). A similar trend is observed in environmental studies (e.g. Matthews et al. 2011; Bellamy et al. 2001). Several reviews on systemic research have concluded that although projects claim to have achieved some kind of value, the evidence is merely based on the author's own reflection with minimal formal evaluation (Midgley 2007). Howick and Ackermann (2011) conducted a comprehensive review of multi-method systems applications, and concluded there is often a limited link between a project's rationale, process, and actual outcomes.

Similar to the debate about hard and soft system approaches, there exist two main positions for evaluating systemic interventions (White 2006): Positivist and interpretive positions. Positivist evaluation aims to collect objective data about the efficiency and effectiveness of the methods in practice. This can lead to "universal" evaluations that may applicable across multiple interventions (Rowe and Frewer 2004). On the other side, an interpretive evaluation approach argues that objective evaluation has limited practicality and relevance to gaining insights into worldviews and interpretations. Instead, it frames evaluation as a continual learning process about the methods and how they have been applied in reality (i.e. what worked, what did not work, why). Along the same lines, Checkland and Holwell (1998) argue that recoverability rather than repeatability (of process and results) is to be used as the criterion for evaluating systemic research. For 'recoverability' to be achieved, the whole research activity or intervention, including the methodology to be employed must be made explicit for an outsider.

Recent developments have argued that there is a need for new evaluation theories or frameworks that combine both positivist and interpretive positions into the systemic intervention, such as (Midgley 2007). Towards this goal, a few evaluation frameworks have been developed, such as White's pragmatic theorybased framework (White 2006). Whereas systemic evaluation frameworks have different forms, they can share some common ideas or principles:

- The need to focus on the purpose of the evaluation and how it is meaningful and relevant to the intervention's purpose and participants' worldviews

- The researcher has to be pragmatic about what they can and cannot measure in complex, contested and resource-limited contexts

- Both quantitative information and qualitative insights are essential and complementary means of establishing evidence

- Use of established theories (e.g. a behavioural theory) to support the design of evaluation and/or explain results add rigor and enrich findings

- The evaluative inquiry itself is a systemic and learning process that involves multiple perspectives (e.g. who and what determines successful outcomes). The process needs to involve continuous exploration of the: purpose, context, and methods and how they link together. 


\subsection{Systems Approaches in Practice and Learning Lessons}

So far, we have given a theoretical overview of systems approaches. Now, we complement the picture by giving the reader a feel for applications of systems approaches in natural resource management in general because of the very lack of groundwater-specific studies. Paucar-Caceres and Espinosa (2011) surveyed systems applications in environment and sustainability areas published in leading OR/MS journals, and concluded that the majority of applications belong to the hard view, with very few soft and critical approaches.

In this section, we present a selection of case studies. We aim to shed some light on elements in the context of each case study (i.e. purpose and methods) that can be relevant in groundwater systems. We hope that this may encourage the reader to think whether and how they can make use of the systems approach in their groundwater applications. We selected case studies to represent different forms and purposes of systems methodologies (See Table 24.2) where:

- Form: single and multi-method interventions where multi-method cases present different combinations of methods (hard, soft, and critical)

- Purpose: intervention's aim is to develop an end-product (e.g. decision support tool), or a process (e.g. a medium for learning and exchanging views)

\subsubsection{Support Community Engagement in Water Conservation Policies in New Zealand (Foote et al. 2006)}

\subsubsection{Context, Purpose, and Design}

The study takes place in a water-stressed town in New Zealand where water security stands as a contentious issue between government agencies and the local community as a result of the failure of successive policies to provide a satisfactory solution to ongoing water shortages. The study starts with the premise that effective implementation of water conservation policies depends on the collaboration of all stakeholders and interest groups. The purpose of the study is to provide a legitimate participatory process for engaging stakeholder groups in evaluating water conservation policies employed. Legitimacy is sought by involving independent third party scientists who are trusted to bring different views to the negotiation table.

Table 24.2 Summary of case studies reviewed as part of this chapter

\begin{tabular}{l|l|l|l|l}
\hline & & & $\begin{array}{l}\text { (Powell and } \\
\text { Osbeck } \\
2010)\end{array}$ & $\begin{array}{l}\text { (Larsen } \\
2011)\end{array}$ \\
\hline Form & $\begin{array}{l}\text { (Foote et al. 2006) } \\
\text { Multi-method } \\
\text { boundary critique } \\
\text { +rich picture) }\end{array}$ & $\begin{array}{l}\text { Multi-method (system } \\
\text { dynamics + cognitive } \\
\text { mapping) }\end{array}$ & $\begin{array}{l}\text { Soft systems } \\
\text { methodology }\end{array}$ & $\begin{array}{l}\text { Critical } \\
\text { systems } \\
\text { heuristics }\end{array}$ \\
\hline Purpose & Process-driven & Product-driven & $\begin{array}{l}\text { Product- } \\
\text { driven }\end{array}$ & $\begin{array}{l}\text { Process- } \\
\text { driven }\end{array}$ \\
\hline
\end{tabular}


In response to the perceived tension, authors foresee the potential of using a boundary critique (Midgley 2000) method to: (1) make the problem definition explicit from a variety of viewpoints; (2) identify areas of agreement, disagreement, marginalisation, and sources of conflicts among stakeholder groups; and (3) guide how problem structuring methods are selected, used and mixed in the case study, and identify implications for inclusion, exclusion, and marginalisation of issues and stakeholders. Authors used interviews, rich pictures and scenario planning workshops to identify and share a multi-perspective evaluation of water policies. Results from using boundary critique show that the conflict about the effectiveness of water conservation measures is rooted in the tension between the pro-development and anti-development values of citizens, and that the debates about water policies cannot be "decoupled" from the "wider debate on the desirability of economic development."

Later in the process, authors reported facing an "ethical dilemma" about the credibility of their research given the decision of policy officers to overlook issues raised by the community (i.e. economic development impacts on water security), and their unwillingness to discuss all the information identified through the engagement process. However, authors decided to think strategically by keeping the process alive, building strategic relationships with key parties, and exploring potential opportunities to establish more open dialogue in the future.

\subsubsection{Evaluation}

Reflecting on the methods used, authors noted that systemic intervention can establish a "sound process" of stakeholder engagement, but it does not necessarily guarantee "win-win outcomes for all." They found that boundary critique provides a useful way for exploring values and boundaries. However, results should not be taken for granted in that there are limits to the method's capacity to elicit values and boundaries.

Whereas the paper is transparent about the methods used, it does not justify how the boundary critique method informed the choice to use rich pictures as problem structuring, although the justification of how methods were selected was as an explicit objective at the outset.

Reflecting on the process outcomes, authors perceived the project as a success because it improved understanding and dialogue as expressed by participating groups. Quotes are used to establish evidence, for example: "The decision-making tools...have allowed a wide range of stakeholders to be actively involved in the decision-making process. The methods employed have provided a non-threatening environment for stakeholders to express their views and this participation has led to general acceptance of the consultation outcomes." In addition, the evidence that the client invited the authors to do more work in the area supported the project's success.

\subsubsection{Relevance to Groundwater Research and Management}

This work has a strong relevance for community engagement in groundwater planning. For example, the concept of acceptable or sustainable aquifer yield is 
underpinned by a judgment about the spatial boundaries (e.g. geographic area, aquifer), temporal boundaries (e.g. planning cycle), administrative and institutional boundaries (e.g. government levels), value boundaries (e.g. social, economic, and environmental groups), and knowledge boundaries (e.g. scientific vs. local). Who makes these judgments? How are these judgments made? Are judgments and their implications transparent to all stakeholders or hidden and scattered across the governance system? In a sound and legitimate planning process, these questions need to be identified and negotiated among stakeholder and interest groups. Boundary critique can be a useful method to facilitate these discussions.

\subsubsection{Communicating About Water Security Issues in the Australian Capital Territory (EISawah 2010)}

\subsubsection{Context, Purpose, and Design}

The study is based on three premises: (1) people have over-simplified mental models about the causal interactions that drive the behaviour of a water resource; (2) flawed and inaccurate mental models may lead to less informed decisions and attitudes towards water management policies and conservation measures; and (3) the design of effective communication tools needs to be based on sound understanding of such mental models, and best ways to improve them. The purpose of this work was to develop an interactive dynamic simulator that could be used to inform and improve the mental models that water users and managers have about the complexity and uncertainty surrounding the future of water security in the Australian Capital Territory. A cognitive mapping method was used to elicit, analyse, and visualise the mental models of water users and managers, specifically in relation to misperceptions and erroneous assumptions, sources of conflicts and communication gaps.

Although managers frequently point out the need to "get the community on board" and for two-way communication, they were reluctant to engage in open discussion groups, indicating that to do so would be overly confronting and excessively time consuming. Yet, they welcome the use of a model as an online educational tool to improve public understanding about the complexities of water management. Given that the primary purpose of the project was developing a modelling tool, the author had to find other data collection and validation methods (e.g. interviews and electronic data sharing methods) to share results and gain feedback. Based on these data, a series of conceptual and numerical system dynamics models were used to develop an interactive simulator that can be used to check the dynamic coherence of elicited mental models and views. A transparent flow of information from cognitive mapping, to conceptual, and then numerical system dynamics models helps users relate their thinking to the end product, and makes the modeller be explicit about the modelling assumptions. 


\subsubsection{Evaluation}

The author uses both self-reflection and pilot experiments to evaluate the modelling process (e.g. transparency, relevance) and its outcomes (e.g. improving the mental models that water users and managers have before and after interacting with the simulator). The author reported that the process allowed for identifying the different perspectives and mental model without prior assumptions. However, the process was limited to only two stakeholder groups, and did not address any of the power relationships in the system and how they may affect policy making. The use of rigorous experiments to evaluate the learning outcomes gives an understanding of what particular perceptions the model can influence.

\subsubsection{Relevance to Groundwater Research and Management}

This work has two key implications for communication and modelling in groundwater management systems. First, the invisible nature of groundwater resources compounded by lack of scientific understanding about the system breeds misconceptions among lay people about the resource's nature, and how it changes (e.g. the myth of underground rivers). Grounded on cognitive psychology, cognitive mapping enables in-depth understanding of these mental models and their implications for attitudes and behaviours.

Secondly, from a modelling viewpoint, modellers often select the boundary of the system to be modelled (what to model) through "ignorance and/or politics" (Eden 1994). The ignorance option is the default for most modellers who decide to ignore the problem complexity and model what they think important to model. Or alternatively, modellers may choose what to model based on how individuals or groups in power (e.g. experts, policy makers and scientists) define the problem. As an alternative, cognitive mapping provides a cognitive approach for modelling where the modeller starts the modelling process by seeking the idiosyncratic views of problem owners. The decision of "what to model" naturally flows from the way problem owners think about the problem. The modelling progression provides better ways of incorporating stakeholder's views and mental models into models.

\subsubsection{Stakeholder Realities in Mangrove Rehabilitation Processes in Southeast Asia (Powell and Osbeck 2010)}

\subsubsection{Context, Purpose, and Design}

The project starts with the premise that "underlying problem definition" significantly affects the design of initiatives to rehabilitate the mangrove forests in East Kalimantan, Indonesian Borneo. Soft systems methodology is used to support the critique of the rehabilitation planning process from the perspective of different stakeholders in the system. 


\subsubsection{Evaluation}

The authors did not reflect thoroughly on the choice and use of their method, but the general impression is that the method was successful in eliciting multiple perspectives and understanding the differences between them.

\subsubsection{Relevance to Groundwater Research and Management}

Groundwater planning is often evaluated from a policy compliance perspective, judging its success from a policy maker's viewpoint. The use of SSM may provide multiple lenses for incorporating other views, especially of those who will implement and be affected by the policy. Some of the differences in viewpoint in this mangrove rehabilitation case transfer to a groundwater management context. There is conflict in objectives between scales, particularly national, state, district and individual, and between groups. Each group adjusts their behaviour to cope with this conflict, leading to unintended consequences and failure to meet objectives. This paper concludes: "The owners' worldview has been shaped by the widely accepted regional assumption that there are strong linkages between the ecological services provided through the rehabilitation of mangroves and the livelihoods of local coastal communities contrary to the assumption, the implementation of this worldview has led to a transformation that neither promotes the cause of conservation nor contributes to sustainable livelihoods of local community. Rather, the beneficiaries have been a private elite. The victims have been the most marginalized in the community and ultimately the ecosystem in which these processes are nested." The distributed nature of groundwater pumping and use can lead to similar self-organising behaviour at multiple scales. Understanding the points of view of different groups can help the plan to avoid such failures.

\subsubsection{Facilitate Stakeholder Dialogue About Coastal Conservation Policies in the Philippines (Larsen 2011)}

\subsubsection{Context, Purpose, and Design}

The study takes place in the northern Philippines where there are growing concerns about overfishing, a declining fisheries industry, low community engagement in integrated coastal management, and hidden agendas overshadowing coastal planning. Within the context of existing involvement in stakeholders in planning, the study aims to facilitate dialogue as a process of social learning, to allow sharing of multiple perspectives on defining the problem and its solutions. The ultimate social learning aim is to enable "stakeholder self-organization." The researcher planned to use Critical Systems Heuristics (CSH, (Ulrich 1994)) to facilitate boundary critique and "provide a 'liberating language' for citizens." However, "participants commented about the rigidity [of $\mathrm{CSH}$ ] and felt constrained by [its] structure". The author decided to use CSH in an exploratory sense with some communicative tools, such as Venn diagrams and mind mapping. 


\subsubsection{Evaluation}

The researcher reflected on the process and concluded that the success of any method is highly dependent on context and implementation. The process was modified as it progressed based on feedback from participants. Underlying boundary problems were identified. However, the paper does not say how the process ended.

The research is built on solid theory, states a clear goal to be evaluated and maintains a reflective approach to both. While we do not know the end outcome, this is a good representation of a well-performed system intervention

\subsubsection{Relevance to Groundwater Research and Management}

Fisheries and groundwater resources are both shared resources, resulting in similar problems of degradation of the resource in a 'tragedy of the commons' when individuals do not have strong feedback on the effect of their actions on the resource. In both fisheries and groundwater management, this has commonly been dealt with through "command-and-control management," where individual actions are regulated by law. Opposition to this arrangement has led to "a shift towards increased stakeholder participation." However, these altered arrangements have their own weaknesses. This paper's attempt to support "social learning for self-organisation" can therefore also be useful in groundwater management, to establish new relationships or restructure existing ones to allow people affected by resource degradation or resource management to participate. The paper supports the claim that tools that help stakeholders participate in management must be used within a broader systems approach, allowing the process to evolve as new information is gained. Addressing the complexity of the human dimension cannot be a simple recipe, "a continuous reconstruction of the process and its assumptions was necessary."

\subsection{Lessons Learnt}

In this section, we share some of the lessons for applying systems thinking interventions, which are manifested in the presented case studies.

First, no single discipline can provide all the answers to addressing human aspects of groundwater management. In particular, systems practitioners and researchers should not think or present their methodologies as being the "most effective", or most comprehensive, pluralistic or holistic (otherwise, they would have fallen into the managerialism thinking trap themselves!). Instead, researchers should have a reflective spirit where they fully understand the strengths and limitations of different methods, and communicate openly about implications for the process and its outcomes.

Second, the effectiveness of a method is strongly dependent on purpose, context and implementation. Whereas most (if not all) systems interventions end up developing both processes and products, it is essential for the researcher to have a clear 
understanding of the primary focus of the intervention (i.e. process-driven or product-driven). This influences process design, including: choices of methods, ways to mix them, evaluation design, as well as strategies to cope with gatekeepers and lack of information.

Third, existing literature on the theory and practice of systems approaches provide rich guidance on how to select, design and implement methods. While practitioners and researchers need to be aware and be explicit about their research's theoretical and methodological stance, they still need to be creative about how they adapt and localise the approach for their case study requirements and constraints.

Finally, incorporating human elements into analysis brings up challenges that often need to be overcome by modifying the existing approach. For example, there may be times where stakeholder groups (as individuals or groups) will act as gatekeepers and try to influence or even block the process and its potential outcomes. It is essential for researchers undertaking this type of research to identify those gatekeepers and develop techniques to work around challenges, such as by looking for other information sources, building trust with key parties, and instituting flexible arrangements to accommodate concerns.

\subsection{Conclusions}

Groundwater management issues present a serious challenge partly because of the complexity and uncertainty that human elements (i.e. cognitive, social, cultural and political) bring into the problem, as well as our limited capacity to fully comprehend and deal with such elements and their interactions with the biophysical systems. Whereas there is a wide recognition of the importance of stakeholder participation for the design and implementation of effective policies, the ongoing depletion of groundwater and disputes surrounding management policies suggest the need for better participatory mechanisms. This raises the question of how human elements can be incorporated into groundwater policies. Whereas there is no single discipline that can provide answers for such crucial research and policy questions, this chapter argues that systems thinking (especially soft and critical approaches) has the potential to provide a framework of theories, methods and example applications to help incorporate human elements into groundwater management and research. This chapter aims to give an overview of systems thinking by firstly describing the theory, distinguishing between hard, soft and critical systems thinking approaches. Secondly, we discussed the importance of mixing methods from these approaches and evaluating 'process' and 'outcomes' when applying them. Thirdly, we reviewed four example applications, and highlighted their relevance to groundwater management systems. Together, these three elements indicate how the framework of systems thinking can help with a number of issues that manifest themselves in groundwater management and research, including: understanding and learning to account for different points of view in planning; understanding how groups affected by a change might respond; helping to enhance 
participants' view of the problem; exploring conflict; and critiquing existing management and groundwater use arrangements with a view to improving them.

Open Access This chapter is distributed under the terms of the Creative Commons AttributionNoncommercial 2.5 License (http://creativecommons.org/licenses/by-nc/2.5/) which permits any noncommercial use, distribution, and reproduction in any medium, provided the original author(s) and source are credited.

The images or other third party material in this chapter are included in the work's Creative Commons license, unless indicated otherwise in the credit line; if such material is not included in the work's Creative Commons license and the respective action is not permitted by statutory regulation, users will need to obtain permission from the license holder to duplicate, adapt or reproduce the material.

\section{References}

Ackoff R (1974) Redesigning the future: a systems approach to societal problems. Wiley, New York

Ayvaz MT, Elçi A (2014) Groundwater recharge rate and zone structure estimation using PSOLVER algorithm. Ground Water 52(3):434-447

Beer S (1989) Viable system model. Wiley, Chicester

Bellamy JA, Walker DH, Mcdonald GT et al (2001) A systems approach to the evaluation of natural resource management initiatives. J Environ Manage 63:407-423

Bosch OJH, King CA, Herbohn JL et al (2007) Getting the big picture in natural resource management-systems thinking as 'method' for scientists, policy makers and other stakeholders. Syst Res Behav Sci 24:217-232

Checkland P (1981) Systems thinking, systems practice. Wiley, Chichester

Checkland P (1983) O.R. and the systems movement: mappings and conflicts. J Oper Res Soc 34:661-675

Checkland P (1985) From optimizing to learning: a development of systems thinking for the 1990s. J Oper Res Soc 36:757-767

Checkland P (1999) Soft systems methodology in action. Wiley, New York

Checkland P (2001) Soft systems methodology. In: Rosenhead J, Mingers J (eds) Rational analysis for a problematic world. Wiley, Chichester, pp 61-89

Checkland P, Holwell S (1998) Action research: its nature and validity. Syst Pract Action Res 11:9-21

Churchman CW (1970a) The design of inquiring systems. Basic Books, New York

Churchman CW (1970b) Operations research as a profession. Manag Sci 17:B37-B53

Dando M, Bennett P (1981) A Kuhnian crisis in management science? J Oper Res Soc 32:91-103

Eden C (1994) Cognitive mapping and problem structuring for system dynamics model building. Syst Dyn Rev 10:257-276

Eden C, Ackermann F (1998) Making strategy: the JOURNEY of strategic management. Sage Publications, London

ElSawah S (2010) The use of integrated modelling for learning and communicating about water issues in the Australian Capital Territory. University of New South Wales, Canberra

Flood RL (2010) The relationship of 'systems thinking' to action research. Syst Pract Action Res 23:269-284

Foote JL, Gregor JE, Hepi MC et al (2006) Systemic problem structuring applied to community involvement in water conservation. J Oper Res Soc 58:645-654

Howick S, Ackermann F (2011) Mixing OR methods in practice: past, present and future directions. Eur J Oper Res 215:503-511 
Ison R, Röling N, Watson D (2007) Challenges to science and society in the sustainable management and use of water: investigating the role of social learning. Environ Sci Pol 10:499-511

Jackson MC (1999) Towards coherent pluralism in management science. J Oper Res Soc 50:12-22

Jackson MC (2006) Creative holism: a critical systems approach to complex problem situations. Syst Res Behav Sci 23:647-657

Kotiadis K, Mingers J (2006) Combining PSMs with hard OR methods: the philosophical and practical challenges. J Oper Res Soc 57:856-867

Larsen R (2011) Critical systems thinking for the facilitation of conservation planning in Philippine coastal management. Syst Res Behav Sci 28:63-76

Mason R, Mitroff I (1981) Challenging strategic planning assumptions: theory, cases and techniques. Wiley, New York

Matthews KB, Rivington M, Blackstock K et al (2011) Raising the bar?-The challenges of evaluating the outcomes of environmental modelling and software. Environ Model Software 26:247-257

Midgley G (1990) Creative methodology design. Systemist 12:108-113

Midgley G (1992) Pluralism and the legitimation of systems science. Syst Pract Action Res 5:147-172

Midgley G (2000) Systemic intervention: philosophy, methodology, and practice. Springer, New York

Midgley G (2007) Towards a new framework for evaluating systemic and participative methods. In: 51st annual meeting of the ISSS pp 1-21

Midgley G, Reynolds M (2004) Systems/operational research and sustainable development: towards a new agenda. Sustain Dev p 57

Midgley G, Cavana RY, Brocklesby J et al (2013) Towards a new framework for evaluating systemic problem structuring methods. Eur J Oper Res 229:143-154

Mingers J (1997) Multi-paradgim multimethodology. In: Mingers J, Gill A (eds) Multimethodology. Wiley, Chichester, New York, pp 1-20

Mingers J (2000) Variety is the spice of life: combining soft and hard OR/MS methods. Int Trans Oper Res 7:673-691

Mingers J (2003) A classification of the philosophical assumptions of management science methods. J Oper Res Soc 54:559-570

Mingers J, Brocklesby J (1997) Multimethodology: towards a framework for mixing methodologies. Omega 25:489-509

Mingers J, Leroy W (2010) A review of the recent contribution of systems thinking to operational research and management science. Eur J Oper Res 207:1147-1161

O'brien F, Meadows M (2007) Developing a visioning methodology: visioning choices for the future of operational research. J Oper Res Soc 58:557-575

Paucar-Caceres A, Espinosa A (2011) Management science methodologies in environmental management and sustainability: discourses and applications. J Oper Res Soc 62:1601-1620

Powell N, Osbeck M (2010) Approaches for understanding and embedding stakeholder realities in mangrove rehabilitation processes in Southeast Asia: lessons learnt from Mahakam Delta, East Kalimantan. Sustain Dev 18:260-270

Reynolds M (2011) Bells that still can ring: systems thinking in practice. In: Tait A, Richardson K (eds) 1st international workshop on complex systems thinking and real world applications. Emergent Publications, Litchfield Park, pp 327-349

Richardson S, Evans R, Harrington G (2011) Connecting science and engagement: setting groundwater extraction limits using a stakeholder-led decision-making process. In: Connell D, Grafton RQ (eds) Basin futures water reform in the Murray-Darling Basin. ANU, Canberra

Rittel H (1972) On the planning crisis: systems analysis of the 'first and second generations'. Bedrifts Okonomen 8:390-396

Rosenhead J, Mingers J (2001) A new paradigm of analysis. In: Rosenhead J, Mingers J (eds) Rational analysis for a problematic world. Wiley, Chichester, pp 1-19 
Rowe G, Frewer L (2004) Evaluating public participation exercises: a research agenda. Sci Technol Hum Values 29:512-556

Ulrich W (1994) Critical heuristics of social planning: a new approach to practical philosophy. Wiley, Chichester

Ulrich W (2000) Reflective practice in the civil society: the contribution of critically systemic thinking. Reflect Pract 1:247-268

Von Bertalanffy L (1950) An outline of general system theory. Br J Philos Sci 1:134-165

White L (2006) Evaluating problem-structuring methods: developing an approach to show the value and effectiveness of PSMs. J Oper Res Soc 57:842-855

White L, Taket A (1997) Critiquing multimethodology as metamethodology: working towards pragmatic pluralism. In: Mingers J, Gill A (eds) Multimethodology: the theory and practice of combining management science methodologies. Wiley, Chichester, pp 379-405

Zhu Z (2011) After paradim: why mixing-methodology theorising fails and how to make it work again. J Oper Res Soc 62(4):784-798 